\title{
Inhibition of Resting Potassium Conductances by Long- Term Activation of the NO/cGMP/Protein Kinase G Pathway: A New Mechanism Regulating Neuronal Excitability
}

\author{
David González-Forero, ${ }^{1}$ Federico Portillo, ${ }^{1,2}$ Laura Gómez, ${ }^{1}$ Fernando Montero, ${ }^{1}$ Sergey Kasparov, ${ }^{2}$ and \\ Bernardo Moreno-López ${ }^{1}$ \\ 1Área de Fisiología, Facultad de Medicina, Universidad de Cádiz, 11003 Cádiz, Spain, and ²Department of Physiology, School of Medical Sciences, \\ University of Bristol, Bristol BS8 1TD, United Kingdom
}

\begin{abstract}
Glutamate-induced excitotoxicity, the most common pathological mechanism leading to neuronal death, may occur even with normal levels of glutamate if it coincides with a persistent enhancement of neuronal excitability. Neurons expressing nitric oxide (NO) synthase (NOS-I), which is upregulated in many human chronic neurodegenerative diseases, are highly susceptible to neurodegeneration. We hypothesized that chronic production of NO in damaged neurons may increase their intrinsic excitability via modulation of resting or "leak" $\mathrm{K}^{+}$currents. Peripheral XIIth nerve injury in adult rats induced de novo NOS-I expression and an increased incidence of lowthreshold motor units, the latter being prevented by chronic inhibition of the neuronal NO/cGMP pathway. Accordingly, sustained synthesis of NO maintained an enhanced basal activity in injured motoneurons that was slowly reverted (over the course of 2-3 h) by NOS-I inhibitors. In slice preparations, persistent, but not acute, activation of the NO/cGMP pathway evoked a robust augment in motoneuron excitability independent of synaptic activity. Furthermore, chronic activation of the NO/cGMP pathway fully suppressed TWIK-related acid-sensitive $\mathrm{K}^{+}$(TASK) currents through a protein kinase $\mathrm{G}$ (PKG)-dependent mechanism. Finally, we found evidence for the involvement of this long-term mechanism in regulating membrane excitability of motoneurons, because their pH-sensitive currents were drastically reduced by nerve injury. This NO/cGMP/PKG-mediated modulation of TASK conductances might represent a new pathological mechanism that leads to hyperexcitability and sensitizes neurons to excitotoxic damage. It could explain why de novo expression of NOS-I and/or its overexpression makes them susceptible to neurodegeneration under pathological conditions.
\end{abstract}

Key words: hypoglossal motoneurons; nerve injury; neuronal excitability; NOS-I upregulation; TASK channels; neurodegenerative diseases

\section{Introduction}

Disturbance of intracellular $\mathrm{Ca}^{2+}$ homeostasis is a central event in glutamate-induced excitotoxicity, the major mechanism of neuronal death caused by brain injury, ischemia, or neurodegenerative diseases (Lipton, 2004; Zhang et al., 2006). Excitotoxic damage may occur even with normal levels of glutamate if the normal block of NMDA receptors by $\mathrm{Mg}^{2+}$ is relieved, a condition that would potentiate $\mathrm{Ca}^{2+}$ influx through these receptors (Lipton, 2004). Consequently, sustained changes in excitability and membrane potential $\left(V_{\mathrm{m}}\right)$ induced by neuronal injury (González-Forero et al., 2004a,b) might exacerbate excitotoxic processes. Understanding of the mechanisms that make neurons

Received May 5, 2006; revised April 18, 2007; accepted April 30, 2007.

This work was supported by grants from the Ministerio de Educación y Ciencia, Spain (SAF2005-00585) and the Consejería de Innovación, Ciencia, y Empresa from the Junta de Andalucía, Spain (CTS-844), both cofinanced by Fondo Europeo de Desarrollo Regional (B.M.-L.) and British Heart Foundation Grant RG/02/011 (S.K.). F.P. was supported by personal fellowship from Secretaría de Estado de Educación y Universidades, Spain (PR2004-0419). We thank Dr. C. Estrada for critical reading of this manuscript and José Ramón Aracama for his technical assistance.

Correspondence should be addressed to Dr. Bernardo Moreno-López, Área de Fisiología, Facultad de Medicina, Plaza Falla 9, 11003 Cádiz, Spain. E-mail: bernardo.moreno@uca.es.

D0I:10.1523/JNEUROSCI.1019-07.2007

Copyright $\odot 2007$ Society for Neuroscience $\quad$ 0270-6474/07/276302-11\$15.00/0 susceptible to excitotoxic death is of great basic and clinical relevancy. Upregulation and/or de novo expression of the neuronal isoform of nitric oxide (NO) synthase (NOS-I), which synthesizes the highly reactive gas $\mathrm{NO}$, is a common hallmark of several human chronic neurodegenerative conditions, such as Parkinson's and Alzheimer's diseases and amyotrophic lateral sclerosis (ALS) (Moreno-López and González-Forero, 2006). Increased levels of NO have also been detected in animal models of stroke and neurodegeneration, which are associated with excitotoxic cell death (Lipton, 2004; Zhang et al., 2006). Furthermore, NOSI-expressing neurons are highly susceptible to neurodegeneration (Thorns et al., 1998). NO physiologically regulates neuronal excitability by modulating diverse ionic channels through soluble guanylyl cyclase (sGC)/protein kinase G (PKG) activation (Ahern et al., 2002). However, it is unknown whether persistent activity of the NO/cGMP pathway is causally related to the enhanced neuronal excitability after injury.

Neuronal excitability is a dynamic rather than fixed variable, which allows adjustment of postsynaptic sensitivity to afferent activity. Modulation of resting $\mathrm{K}^{+}$currents, which are fundamental in determining resting $V_{\mathrm{m}}$ and input resistance $\left(R_{\mathrm{N}}\right)$, has a profound impact on neuronal excitability. The KCNK family of 
two-pore-domain $\mathrm{K}^{+}$channels plays a major role in control of both variables in mammalian cells (Bayliss et al., 2003). Among them, the $\mathrm{pH}$-sensitive subunits TWIK-related acid-sensitive $\mathrm{K}^{+}-1$ (TASK-1) and TASK-3 are widely coexpressed throughout the brain, with particularly high expression levels in motoneurons (Talley et al., 2001). TASK currents can be modulated by multiple neurotransmitter systems, including those associated with awakening and alertness states. This could serve to couple neuronal responsiveness to afferent drive and behavioral status (McCormick and Bal, 1997; Talley et al., 2000; Bayliss et al., 2003). Interestingly, $\mathrm{K}^{+}$channel openers have potential for the treatment of several brain disorders characterized by neuronal hyperexcitability, such as spasticity or epileptic seizures (Wua and Dworetzky, 2005). Therefore, modulation of TASK channels might potentially represent a new therapeutic strategy, and these channels might become important drug targets.

We show that the autocrine activation of the neuronal $\mathrm{NO}$ / cGMP pathway induced by XIIth nerve injury enhances excitability of the motoneuron pool. In addition, whole-cell recordings from motoneurons demonstrated that chronic, but not acute, stimulation of the NO/cGMP pathway leads to a pronounced increase in intrinsic excitability, via a PKG-mediated inhibition of TASK-like $\mathrm{pH}$-sensitive "leak" $\mathrm{K}^{+}$currents. Accordingly, we describe a new mechanism for regulating neuronal excitability that could be the basis for synaptic potentiation and neuron sensitization to excitotoxic death during neurological disorders.

\section{Materials and Methods}

Animals, obtained from an authorized supplier (Animal Supply Services, University of Cádiz, Cádiz, Spain), were cared for and handled in accordance with the guidelines of the European Union Council (86/609/UE) and the Spanish regulations (BOE 67/8509-12 and BOE 1201/2005) on the use of laboratory animals. Statistical tests applied to each data set are indicated in the figure legends. Data are presented as mean \pm SEM.

\section{In vivo approaches}

Extracellular unitary recordings of hypoglossal motoneurons. Adult male Wistar rats $(250-400 \mathrm{~g})$ were anesthetized with chloral hydrate $(0.5 \mathrm{~g} / \mathrm{kg}$, i.p.), and the right hypoglossal (XIIth) nerve was thoroughly crushed with microdissecting tweezers for $30 \mathrm{~s}$ just proximal to the nerve bifurcation, as described previously (González-Forero et al., 2004b). Animals were allowed to survive $7 \mathrm{~d}$ after surgery and then prepared for extracellular recordings (González-Forero et al., 2004b). Briefly, rats were anesthetized (as above) and additionally injected intramuscularly with atropine $(0.2 \mathrm{mg} / \mathrm{kg})$ and dexamethasone sodium phosphate $(0.8 \mathrm{mg} / \mathrm{kg})$. Teflon-isolated silver bipolar electrodes were fixed around the right XIIth nerves. Trachea, bladder, and femoral artery and vein were cannulated. Subsequently, animals were vagotomized, decerebrated, paralyzed with gallamine triethiodide $(20 \mathrm{mg} / \mathrm{kg}$, i.v., initially; $4 \mathrm{mg} / \mathrm{kg}$, i.v., as needed), and mechanically ventilated. Expired $\mathrm{CO}_{2}$ and $\mathrm{O}_{2}$ were monitored continuously (Eliza duo; Gambro Engström, Bromma, Sweden). During the experiment, the end-tidal $\mathrm{CO}_{2}\left(\mathrm{ET}_{\mathrm{CO} 2}\right)$ was changed ( $\sim 3$ to $\sim 7.5 \%$ ) by adjusting tidal volume and/or respiratory rate. Expired $\mathrm{O}_{2}$ (14-19\%) was always higher than values below which hypoxia-induced alterations have been reported (Hwang et al., 1983). Femoral arterial blood pressure $(95 \pm 15 \mathrm{mmHg})$ and rectal temperature $\left(37 \pm 1^{\circ} \mathrm{C}\right)$ were continuously monitored and kept stable. Glass micropipettes (1-3 M $\Omega$ ), filled with $2 \mathrm{M} \mathrm{NaCl}$, were placed under visual guidance and advanced through the brainstem into the hypoglossal nucleus (HN). The correct position of the micropipette was confirmed by recording the characteristic inspiratory pattern and the presence of the antidromic field potential elicited by electrical stimulation of the ipsilateral XIIth nerve. Hypoglossal motoneurons (HMNs) were identified by their antidromic activation from the XIIth nerve and by the collision test (González-Forero et al., 2004b; Sunico et al., 2005). The electrical signals were amplified and filtered at a bandwidth of $10 \mathrm{~Hz}$ to $10 \mathrm{kHz}$ for display and digitalization purposes. Responses of HMNs were recorded in response to changes in $\mathrm{ET}_{\mathrm{CO} 2}$ from hypocapnic $(\sim 3 \%)$ to hypercapnic $(\sim 7.5 \%)$ conditions. Only inspiratory HMNs discharging at basal conditions $\left(\mathrm{ET}_{\mathrm{CO} 2}=4.8-\right.$ $5.2 \%)$ were considered in this study. Unitary discharge activity, percentages of expired $\mathrm{CO}_{2}$ and $\mathrm{O}_{2}$, and arterial pressure recordings were amplified, filtered, digitized, and stored in a computer using a PowerLab/ 8SP analog-to-digital interface (ADInstruments, Castle Hill, Australia) for off-line analysis. The mean unitary firing rate (mFR) (spikes per second) in each burst was measured over the range of $\mathrm{ET}_{\mathrm{CO} 2}$ tested. Because mFR changed proportionally to alterations in $\mathrm{ET}_{\mathrm{CO} 2}$ (see Fig. $1 \mathrm{~B})$, both parameters were positively correlated using linear regression analysis (see Fig. 1C). It was thus possible to obtain an equation characterizing the behavior of an $\mathrm{HMN}$ in response to changes in $\mathrm{ET}_{\mathrm{CO} 2}$ : $\mathrm{mFR}=S_{\mathrm{mFR}} \times \mathrm{ET}_{\mathrm{CO} 2}+I_{\mathrm{mFR}}$, where $S$ is the slope (i.e., the neuronal gain or sensitivity of $\mathrm{mFR}$ relative to $\mathrm{ET}_{\mathrm{CO} 2}$ variations), and $I$ is the ordinate intercept (i.e., the theoretical mFR value when $\mathrm{ET}_{\mathrm{CO} 2}=0 \%$ ). Theoretical recruitment threshold (Th) was calculated as the abscissa intercept from the mFR-ET $\mathrm{CO}_{\mathrm{C} 2}$ regression line (see Fig. $1 C$ ).

Administration of NOS and sGC inhibitors. To study the involvement of the NO/cGMP pathway in motoneuron alterations induced by peripheral nerve lesions, injured rats were daily administered (i.p.) with the broad-spectrum NOS inhibitor $N^{\omega}$-nitro-L-arginine methyl ester (LNAME; $90 \mathrm{mg} \cdot \mathrm{kg}^{-1} \cdot \mathrm{d}^{-1}$; Sigma, St. Louis, MO), the inactive stereoisomer D-NAME $\left(90 \mathrm{mg} \cdot \mathrm{kg}^{-1} \cdot \mathrm{d}^{-1}\right.$; Sigma $)$, the relatively specific NOS-I inhibitor 7-nitroindazole (7-NI; $30 \mathrm{mg} \cdot \mathrm{kg}^{-1} \cdot \mathrm{d}^{-1}$; Sigma), or the specific sGC inhibitor $1 H$-[1,2,4] oxadiazolo[4,3-a]quinoxalin-1one (ODQ; $2 \mathrm{mg} \cdot \mathrm{kg}^{-1} \cdot \mathrm{d}^{-1}$; Sigma), beginning on the day of nerve crush. Treatment with 7-NI did not affect arterial blood pressure, whereas L-NAME administration caused a transient elevation of this parameter that returned to control values $6 \mathrm{~h}$ after injection (MorenoLópez et al., 2004). The levels of cerebral NOS-I and endothelial isoform of NOS (NOS-III) remained as in control animals after chronic treatment with L-NAME (Moreno-López et al., 2004). Perfusions or recording sessions were conducted at least $18 \mathrm{~h}$ after the last injection of drugs. To rule out the possibility that systemic NOS inhibition had its own effects on the functional characteristics of HMNs, we studied their firing properties in a separate group of noninjured rats treated with L-NAME $\left(90 \mathrm{mg} \cdot \mathrm{kg}^{-1} \cdot \mathrm{d}^{-1}\right)$ for $7 \mathrm{~d}$.

Electroneurographic recordings of XIIth nerves. In a series of experiments conducted on untreated adult rats at $7 \mathrm{~d}$ after injury, basal activity of XIIth nerves was monitored continuously for a minimum period of $8 \mathrm{~h}$, from $1 \mathrm{~h}$ before to $7 \mathrm{~h}$ after drug administration. Under ketamine: xylidine anesthesia (35:1 mg/kg, i.m.), both nerves were dissected from experimental animals, and Teflon-isolated silver bipolar electrodes were placed 3-4 mm proximal to their bifurcation. Electrodes were electrically isolated from neighboring tissue with Vaseline jelly and Parafilm. During the recording sessions, supplemental doses of ketamine:xylidine (5:0.2 $\mathrm{mg} \cdot \mathrm{kg}^{-1} \cdot \mathrm{hr}^{-1}, \mathrm{i} . \mathrm{m}$.) were given as necessary to maintain a stable level of anesthesia. Spontaneous activity from both nerves was recorded in monopolar mode, AC coupled, amplified, and filtered ( $10 \mathrm{~Hz}$ to $10 \mathrm{kHz})$. The electroneurographic signals were integrated $(\tau=20 \mathrm{~ms})$, and the area of each burst was determined using a parabola automatically fitted to the integrated burst activity provided by the Chart software (ADInstruments). The ratio between the activities of the crushed relative to the intact nerve was analyzed at $1 \mathrm{~h}$ intervals throughout each experiment and plotted against time. Mean values were calculated from bursts occurring over a period of $5 \mathrm{~min}$ at each time sampled.

In vitro whole-cell recordings from HMNs in brainstem slices Whole-cell patch-clamp experiments were performed on brainstem slices from 6- to 9-d-old animals either intact or lesioned unilaterally at postnatal day 3 (P3). Rat pups were anesthetized by hypothermia (placing on ice for 10-15 min) and decapitated, and their brainstems were quickly removed. Dissection was in ice-cold $\left(<4^{\circ} \mathrm{C}\right)$ sucrose artificial CSF (S-aCSF) bubbled with $95 \% \mathrm{O}_{2}$ and $5 \% \mathrm{CO}_{2}$. S-aCSF composition was as follows (in mM): $26 \mathrm{NaHCO}_{3}, 10$ glucose, $3 \mathrm{KCl}, 1.25 \mathrm{NaH}_{2} \mathrm{PO}_{4}, 2$ $\mathrm{MgCl}_{2}$, and 218 sucrose. Transverse slices (300-400 $\mu$ m thickness) were cut around the obex using a vibratome (Series 1000; Technical Products International, St. Louis, MO). Slices were transferred to normal oxygen- 
ated aCSF (in which sucrose was substituted by $130 \mathrm{~mm} \mathrm{NaCl}$ and $2 \mathrm{~mm} \mathrm{CaCl}_{2}$ ), incubated for $1 \mathrm{~h}$ at $36^{\circ} \mathrm{C}$, and then allowed to stabilize at room temperature $\left(\sim 22^{\circ} \mathrm{C}\right)$ for at least $30 \mathrm{~min}$.

To study the influence of the NO/cGMP/ PKG pathway on the membrane excitability of HMNs, different combinations of activators and/or blockers were added to the bath solution. Either drugs were applied acutely (10 min during recordings) or slices were preincubated with drugs for a minimum of $4 \mathrm{~h}$ before the recordings and also during the recordings ("chronic" treatments). Untreated control slices and those exposed to acute treatments were also maintained for the same $4 \mathrm{~h}$ period in standard aCSF before recordings. To clearly isolate the influence of the NO/cGMP/PKG pathway on intrinsic excitability and avoid possible modulatory effects from afferent synaptic inputs, a series of experiments involving chronic treatments were performed under conditions of minimal levels of synaptic activity. In this protocol, both preincubation and recording were made in a modified aCSF containing low $\mathrm{Ca}^{2+}\left(0.5 \mathrm{~mm} \mathrm{CaCl}_{2}\right)$, high $\mathrm{Mg}^{2+}(6 \mathrm{~mm}$ $\mathrm{MgCl}_{2}$ ), and a mixture of synaptic blockers: bicuculline methiodide (10 $\mu \mathrm{m}$; Sigma), strychnine hydrochloride (0.25 $\mu \mathrm{M}$; Sigma), AP-5 [D(-)-2amino-5-phosphonopentanoic acid; $50 \mu \mathrm{M}$; Tocris Cookson, Ballwin, MO], CNQX (6-cyano-7nitroquinoxaline-2,3-dione; $10 \mu \mathrm{M}$; Tocris Cookson), D-tubocurarine chloride (30 $\mu \mathrm{M}$; Sigma). Because chronic and acute exposure to NO donors resulted in a constant depolarization of HMNs (see Results), we tested the effects of a persistent depolarization on the membrane parameters in a separate group of experiments. In this case, slices were preincubated and recorded with high- $\mathrm{K}^{+}{ }_{\mathrm{aCSF}}(5 \mathrm{~mm} \mathrm{KCl}$ and 1.25 $\mathrm{mM} \mathrm{KH}_{2} \mathrm{PO}_{4}$ ).

After preincubations, the slices were individually transferred into the recording chamber and perfused continuously (at a rate of $2 \mathrm{ml} /$ $\min$ ) with different solutions at $31^{\circ} \mathrm{C}$. Wholecell recordings were obtained from somata of HMNs visually identified based on their location and characteristic size and shape (Talley et al., 2000) using a Nikon (Tokyo, Japan) Eclipse CFI60 microscope equipped with infrared (IR) differential interference contrast, a $40 \times$ waterimmersion objective, and an IR camera system (TILL Photonics, Pleasanton, CA). Patch pipettes were pulled from $1.5 \mathrm{~mm}$ outer diameter borosilicate glass using a PP-830 puller (Narishige, Tokyo, Japan). Patch electrodes (1.5-3 $\mathrm{M} \Omega$ resistance) contained the following (in mM): $17.5 \mathrm{KCl}, 122.5 \mathrm{~K}$-gluconate, $9 \mathrm{NaCl}, 1 \mathrm{MgCl}_{2}, 10$ HEPES, 0.2 EGTA, $3 \mathrm{Mg}$-ATP, and 0.3 GTP-Tris with pH buffered to 7.2. Currentand voltage-clamp recordings were obtained and low-pass Bessel filtered at $10 \mathrm{kHz}$ with a MultiClamp 700B amplifier. Data were digitized at 20 $\mathrm{kHz}$ with a Digidata $1332 \mathrm{~A}$ analog-to-digital converter and acquired using pCLAMP 9.2 software (Molecular Devices, Foster City, CA). Only recordings with access resistance between 5 and $20 \mathrm{M} \Omega$ were considered acceptable for analysis. The access resistance was checked throughout the experiments, and recording was abandoned if it changed $>15 \%$. Series resistance was routinely compensated $65-75 \%$. The pipette offset potential was zeroed before the cells were patched. Leak or liquid junction potentials were not corrected. In the voltage-clamp mode, all tests were performed in presence of tetrodotoxin (TTX; $1 \mu \mathrm{M}$; Alomone Labs,
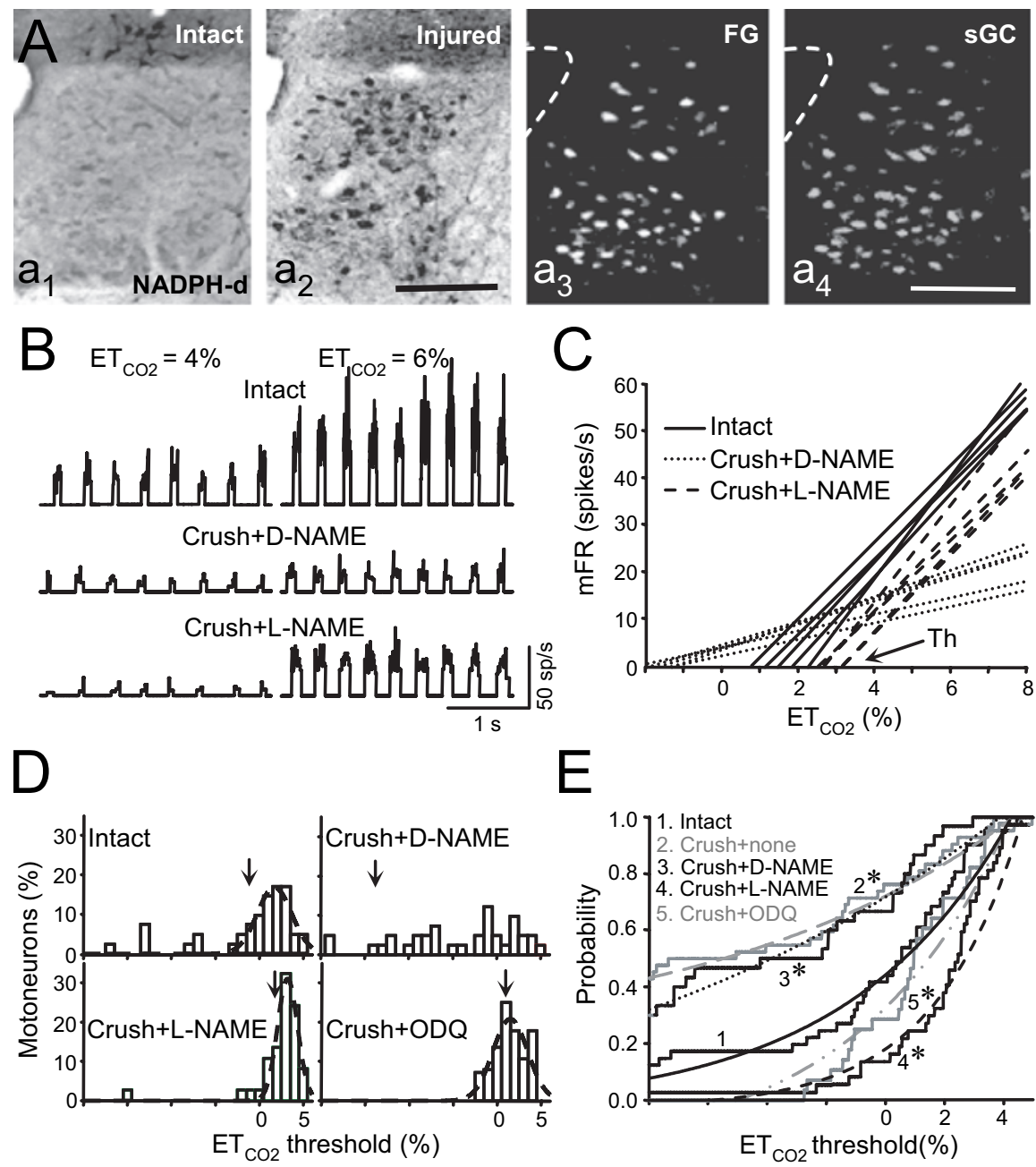

Figure 1. Chronic activation of the N0/CGMP pathway modifies the recruitment distribution of hypoglossal motoneurons after nerve injury in adult rats. $\boldsymbol{A}$, Photomicrographs obtained from coronal brainstem sections showing the induction of a new enzymatic source of N0 and the presence of its target within the HN. $\boldsymbol{a} 1, \boldsymbol{a} 2$, NADPH-d visualized histochemically in sections obtained in control ( $\boldsymbol{a} \mathbf{1})$ and at $7 \mathrm{~d}$ after lesion ( $\boldsymbol{a} \mathbf{2}) . \boldsymbol{a} \mathbf{3}, \boldsymbol{a} 4$, Confocal photomicrographs of a section obtained from a control animal in which HMNs are double labeled with both the retrograde marker $\mathrm{FG}(\boldsymbol{a} \mathbf{3})$ injected in the tongue and sGC antisera (a4) different levels of $\mathrm{ET}_{\mathrm{CO}_{2}}$ concentrations in a control animal and $7 \mathrm{~d}$ after ipsilateral $\mathrm{XIlth}$ nerve crushing in animals receiving chronic treatment with D-NAME or L-NAME. C, Regression lines of $\mathrm{mFR}$ and $\mathrm{ET}_{\mathrm{CO}_{2}}$ obtained from HMNs ( $n=5$ per condition), in control and Xith nerve injury from receiving the specified treatments. The abscissa intercept in the regression line indicates the theoretical recruitment Th for each motor unit. $\boldsymbol{D}$, Distribution histograms of Th obtained in HMNs from control and lesioned $\boldsymbol{E}$, Cumulative probability histograms of Th obtained in control and at $7 \mathrm{~d}$ after lesion receiving the indicated treatments. Histo$0.54 \exp (0.1 x)$; crushed D-NAME, $y=-0.24+0.97 \exp (0.07 x)$; crushed L-NAME, $y=-0.03+0.22 \exp (0.34 x)$; crushed ODQ $y=-0.2+0.53 \exp (0.19 x) .{ }^{*} p<0.05 ;$ Kolmogorov-Smirnov test with respect to the control group.

Jerusalem, Israel). Neurons were initially held near the resting potential $(-65 \mathrm{mV})$, and then voltage-clamp protocols consisting either of depolarizing ramps or command steps were applied. In some experiments, $\mathrm{pH}$ sensitivity of HMNs was evaluated by perfusing sequentially the same cell with aCSF with varying $\mathrm{pH}$ levels ( $\mathrm{pH} 6.2,7.2$, and 8.2). Hydrogen ion concentration was adjusted adding either $\mathrm{HCl}$ or $\mathrm{NaOH}$ to aCSF. In some experiments, responsiveness of HMNs to thyrotropin-releasing hormone (TRH) applications (10 $\mu \mathrm{m}$; superfused for $15 \mathrm{~s}$; Sigma) was tested.

Treatments with drugs that modulate the NO/cGMP/PKG pathway. Two NONOates, NO-generating compounds and a cell-permeable cGMP analog, were used to discriminate between acute and chronic effects of NO on membrane properties. The short-half-life NO donor 

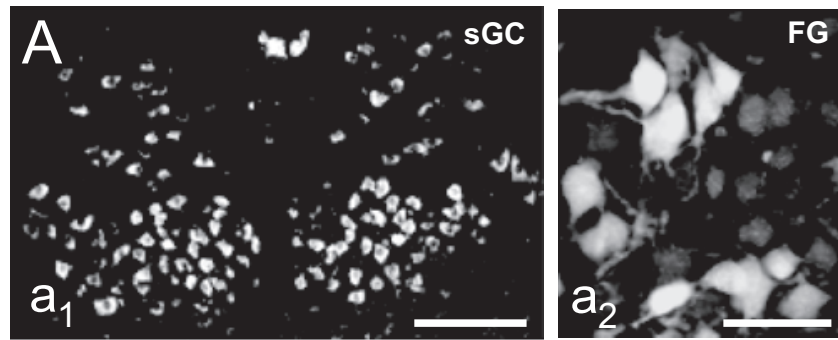

\section{B}
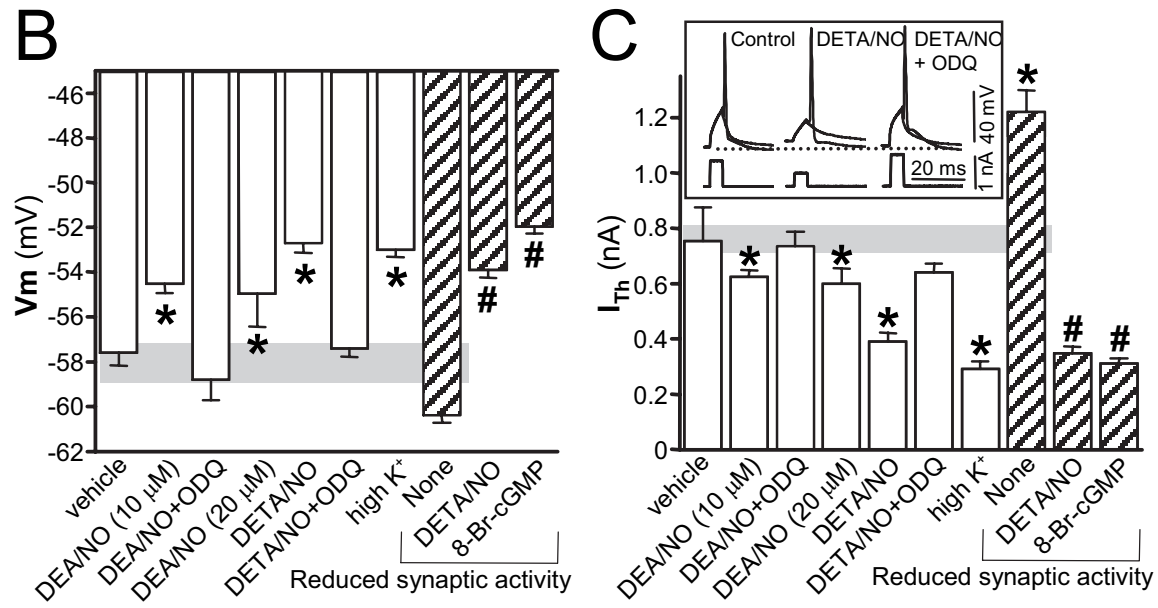

$\mathrm{D}$
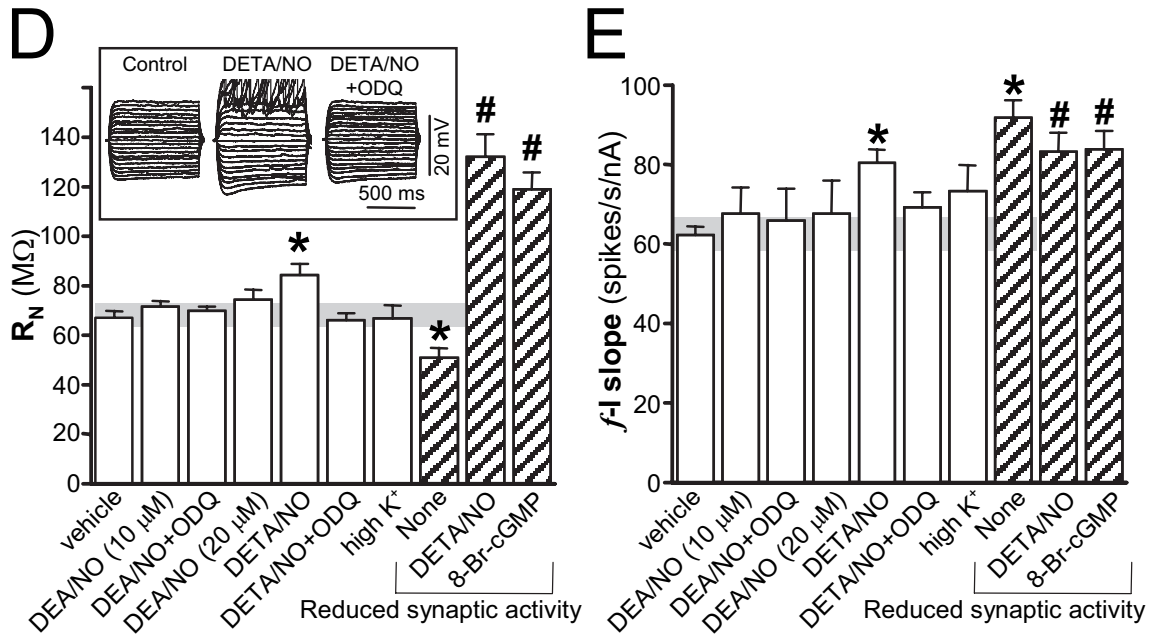

Figure 2. Persistent activation of the NO/CGMP pathway induces a severe increase in the excitability of hypoglossal motoneurons. $\boldsymbol{A}$, Confocal photomicrographs through the HNs obtained from a neonatal rat (P7) immunostained for sGC (a1). a2, a3, An area shown using high magnification demonstrates that all of the HMNs identified by selective retrograde tracing with $\mathrm{FG}(\boldsymbol{a} \mathbf{2})$ also express sGC ( $\boldsymbol{a} 3)$. Scale bars: $\boldsymbol{a} 1,250 \mu \mathrm{m} ; \boldsymbol{a} \mathbf{2}, \boldsymbol{a} \mathbf{3}, 50 \mu \mathrm{m}$. $\boldsymbol{B}-\boldsymbol{E}$, Changes in the $V_{\mathrm{m}}(\boldsymbol{B})$, current threshold for firing $\left(I_{T h} ; \boldsymbol{C}\right)$ mean $R_{\mathrm{N}}(\boldsymbol{D})$, and mean $f-/$ slope $(\boldsymbol{E})$ of HMNs $(n=20-38)$ induced by either acute or chronic incubations with the listed drugs under conditions of normal spontaneous or pharmacologically reduced synaptic activity. $\boldsymbol{C}$, Inset, Examples of voltage responses to short (5 ms) depolarizing current pulses obtained in different HMNs recorded under conditions of normal spontaneous synaptic activity in control or after chronic preincubations with the indicated drugs. The horizontal dotted line marks $-60 \mathrm{mV}$. D, Inset, Voltage responses to a series of depolarizing and hyperpolarizing current pulses ( $1 \mathrm{~s}$ duration, $0.02 \mathrm{nA}$ increments) from different HMNs recorded in control slices or after incubations with the specified drugs under conditions of normal spontaneous synaptic activity. $\boldsymbol{B}-\boldsymbol{E}$, Horizontal gray bars represent means \pm SEM of the control group. Striped bars indicate data obtained under conditions of reduced synaptic activity. ${ }^{*, \#} p<0.05$; one-way ANOVA; post hoc Tukey's test relative to the control groups with spontaneous and reduced synaptic activity, respectively.

2-( $N, N$-diethylamino)-diazenolate-2-oxide (DEA/NO; 10 or $20 \mu \mathrm{M}$; Sigma) or cell-permeable cGMP analog 8-Br-cGMP (1 mM; Sigma) was used for acute applications and added to the bath after controls have been accomplished and superfused for $10 \mathrm{~min}$ before measurements were taken again. For chronic treatments ( $>4$ h exposure), the long-half-life NO donor ( $Z$ )-1-[2-(2-aminoethyl)-N-(2-ammonioethyl)amino]diazen-1-ium-1,2-diolate-NO (DETA/NO; $1 \mathrm{~mm}$; Sigma), the sGC

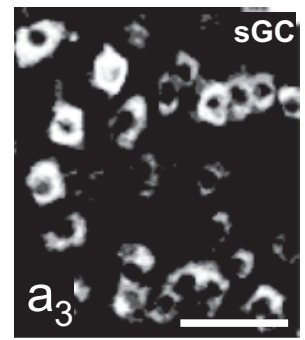

inhibitor ODQ, $(20 \mu \mathrm{M}), 8-\mathrm{Br}-\mathrm{cGMP}(0.1$ $\mathrm{mm})$, and the cell-permeable inhibitor of PKG, guanosine, 3', 5' -cyclic monophosphorothioate, 8-4-chlorophenylthio-, Rp-isomer (Rp-8-pCPT-cGMPS, $10 \mu \mathrm{M}$; EMD Biosciences, La Jolla, CA), were added either alone or in different combinations both to the preincubation and recording solutions.

Data analysis. In current-clamp mode, the resting $V_{\mathrm{m}}$, the current threshold for firing $\left(I_{\mathrm{Th}}\right), R_{\mathrm{N}}$, and the slope of the relationship between average firing frequency and injected current ( $f-I$ curves) were measured. $I_{\mathrm{Th}}$ was determined as the lowest depolarizing current pulse ( $5 \mathrm{~ms}$ ) required to elicit an action potential in $50 \%$ of cases. $R_{\mathrm{N}}$ was calculated from the current-voltage ( $I-V$ ) plots obtained by injecting a series of depolarizing and hyperpolarizing current pulses intracellularly ( $1 \mathrm{~s} ;-0.2$ to 0.2 $\mathrm{nA})$. The resulting data points were then fitted with a least-squares regression line, and $R_{\mathrm{N}}$ was estimated as the slope of the lines. Finally, $f-I$ curves were constructed applying intracellular injections of depolarizing current pulses ( $1 \mathrm{~s}$; steps of $0.02 \mathrm{nA}$ ) and plotting the mFR within each burst against current pulse amplitude.

In voltage-clamp recordings, the holding current $\left(I_{\text {holding }}\right)$ required to keep $V_{\mathrm{m}}$ at -65 $\mathrm{mV}$ was measured. The protocols to obtain $I-V$ relationships consisted either of increasing voltage ramps ( 2 s duration) from -120 to -40 $\mathrm{mV}$ or voltage steps applied in $5 \mathrm{mV}$ increments between -50 and $-120 \mathrm{mV}$ from a baseline holding potential of $-65 \mathrm{mV}$. The slope conductance $\left(G_{\text {slope }}\right)$ was calculated as the slope of the $I-V$ linear fits generated by the ramp protocol within the voltage range of -100 to -40 $\mathrm{mV}$. Similarly, input conductance $\left(G_{\mathrm{N}}\right)$ was determined as the slope of the $I-V$ linear fits obtained from current responses to voltage steps. In this case, the instantaneous component was measured in a time window between the settling of the transient capacitive current and the onset of the time-dependent current $\left(I_{\mathrm{h}}\right), \sim 10$ ms after the onset of the step.

\section{Histological procedures}

Animals were anesthetized with ketamine and xylidine-dihydrothiazine (as above), injected intraventricularly with heparin, and perfused transcardially first with PBS, followed by $4 \%$ paraformaldehyde in $0.1 \mathrm{M}$ phosphate buffer (PB), $\mathrm{pH} 7.4$, at $4^{\circ} \mathrm{C}$. The brains were removed, postfixed for $2 \mathrm{~h}$ in the same fixative solution, and cryoprotected by overnight immersion in $30 \%$ sucrose in $\mathrm{PB}$ at $4^{\circ} \mathrm{C}$. Serial coronal sections (30 $\mu \mathrm{m}$ thick) from brainstem were obtained using a cryostat and stored at $-20^{\circ} \mathrm{C}$ in a cryoprotectant solution (glycerol:PBS, $\mathrm{pH} 7.4$, $1: 1$ in volume).

Nitrergic neurons were identified by NADPH diaphorase (NADPH-d) histochemistry. NADPH-d activity was made visible by incubation of the tissue in a mixture containing $1 \mathrm{~mm} \beta$-NADPH, $1 \mathrm{~mm}$ nitroblue tetrazolium, and $0.1 \%$ Triton $\mathrm{X}-100$ in $0.1 \mathrm{M}$ Tris buffer, $\mathrm{pH}$ 8.0 , for $30 \mathrm{~min}$ at $37^{\circ} \mathrm{C}$. After extensive washing, the tissue was dehydrated, mounted with DePeX (Serva, Heidelberg, Germany), and analyzed under light microscopy. In a separate group, $50 \mu \mathrm{l}$ of a solution containing $1 \%$ of the retrograde tracer aminostilbamidine methanesul- 

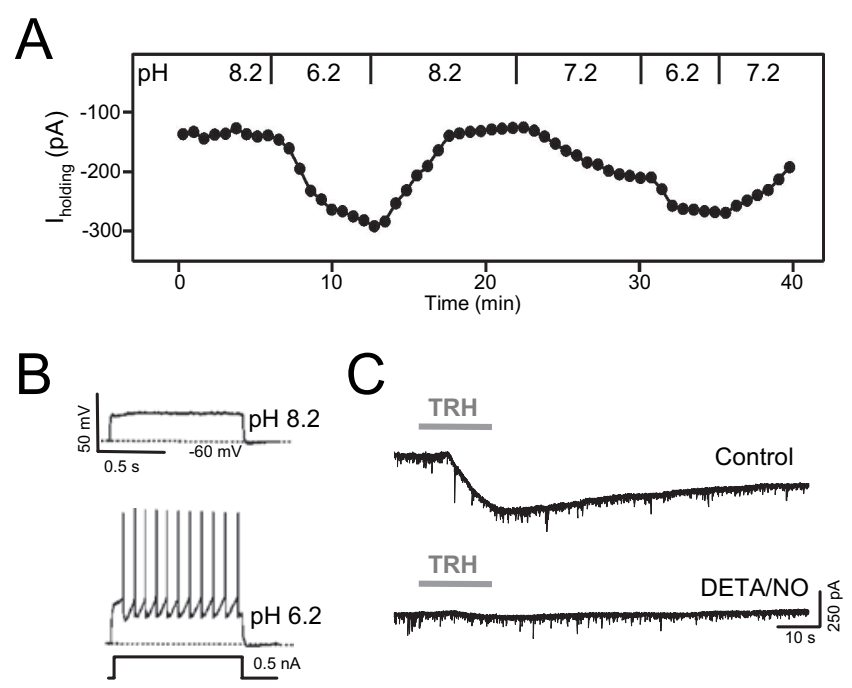

Figure 3. TASK channels as feasible targets for the chronic action of NO. A, Time series illustrating changes in / holding for a representative HMN voltage clamped at $-65 \mathrm{mV}$ in response to variations in extracellular pH. $\boldsymbol{B}$, Voltage responses of a P8 HMN to the same depolarizing current pulse $(1 \mathrm{~s}, 0.5 \mathrm{nA})$ obtained during superfusion with either alkaline $(\mathrm{pH} 8.2)$ or acidic $(\mathrm{pH}$ 6.2) aCSF. In both cases, the baseline membrane potential was kept constant at $-60 \mathrm{mV}$ (dotted line) by DC-current injection through the patch pipette. C, Whole-cell current responses evoked by the application of TRH (10 $\mu \mathrm{m}$ for $15 \mathrm{~s}$ ) in representative HMNs from control and DETA/NO-treated slices. Membrane potential was held at $-65 \mathrm{mV}$.

fonate [FluoroGold (FG); Invitrogen, Eugene, OR] in PBS was injected into the tip of the tongue to identify HMNs. These animals were perfused 5-7 d after the tracer injection. For the analysis of sGC immunostaining, free-floating sections were rinsed in PBS and immersed in 2.5\% (w/v) bovine serum albumin, $0.25 \%(\mathrm{w} / \mathrm{v})$ sodium azide, and $0.1 \%(\mathrm{v} / \mathrm{v})$ Triton $\mathrm{X}-100$ in PBS for $30 \mathrm{~min}$, followed by incubation at $4^{\circ} \mathrm{C}$ with the primary antiserum solution containing a polyclonal antibody raised in goat against sGC $\beta 1$ (1:100; 2 d; Santa Cruz Biotechnology, Santa Cruz, CA). Subsequently, the tissue was rinsed in PBS and incubated for $2 \mathrm{~h}$ at room temperature with an anti-goat IgG conjugated with Cy3 (cyanine 3; 1:400; Jackson ImmunoResearch, West Grove, PA). Finally, sections were washed with PBS and mounted on slides with a solution containing propyl gallate (0.1 mM in PBS:glycerol, 1:9). Omission of the primary antibody resulted in no detectable staining. Immunoreactivity was analyzed using a Leica (Nussloch, Germany) confocal microscope.

\section{Results}

Injured HMNs have the biochemical machinery for autocrine NO signaling

To explain how NO can regulate the functional status of HMNs, it is essential to identify its potential sources and targets within the HN. Although HMNs are normally deficient in NOS-I, its expression can be induced by axon injury (Sunico et al., 2005). To illustrate this change, slices obtained from adult rats were processed for NADPH-d histochemistry to label NOS-expressing structures. Under control conditions, only some scattered nitrergic neurons were observed at various locations throughout the HN (Fig. 1a1). However, $7 \mathrm{~d}$ after XIIth nerve crush, the number of positive cell bodies on side ipsilateral to the injured nerve increased dramatically relative to the intact side (375.5 \pm 7.6 vs $21.1 \pm 4.7 ; n=3$ animals) (Fig. 1a2). We have previously demonstrated that the upregulated isoform was NOS-I (Sunico et al., 2005). The hypothesis of an autocrine modulation would be supported if the major target of NO, the sGC, is also present in HMNs. To test this, HMNs were identified by retrograde tracing with FG (Fig. 1a3) and immunostained for sGC (Fig. 1a4). We found that all FG-positive neurons also expressed sGC, whereas only a small fraction $(<10 \%)$ of sGC-positive cell bodies lacked FG labeling. In conclusion, after injury to the XIIth nerve, HMNs expresses the molecular substrates necessary for autocrine action of the NO/cGMP pathway.

\section{Autocrine action of the NO/cGMP pathway modifies the recruitment scheme of the hypoglossal motor pool in vivo} In vivo recordings showed that $\mathrm{mFR}$ of $\mathrm{HMNs}$ was positive and linearly related to changes in $\mathrm{ET}_{\mathrm{CO} 2}$ (Fig. $1 \mathrm{~B}, \mathrm{C}$ ). Recruitment $\mathrm{Th}$ for each recorded hypoglossal motor unit can be defined as the theoretical $\mathrm{ET}_{\mathrm{CO} 2}$ concentration at which the motoneuron begins to discharge (that is, the abscissa intercept in the mFR-ET $\mathrm{CO}_{\mathrm{C}}$ regression line) (Fig. $1 C$, Th). In the control group, the mean Th was $-1.2 \pm 0.8 \%$, and its distribution was well fitted with a Gaussian function (Fig. 1D). This recruitment scheme was preserved in both the sham-operated and L-NAME-treated intact groups (data not shown). However, $7 \mathrm{~d}$ after nerve crush, distribution of Th was distorted, and the mean Th was reduced $(-13.8 \pm 5.2 \%)$. Cumulative sum histograms showed that in the insulted group, the proportion of motor units that would have been active at $0 \%$ of $\mathrm{ET}_{\mathrm{CO} 2}(75.6 \%)$ was much higher than in the control pool (41.5\%) (Fig. $1 E$ ). These alterations were indeed accompanied by an expansion of the recruitment range and a reduction in the recruitment gain (i.e., the recruitment rate throughout the whole $\mathrm{ET}_{\mathrm{CO} 2}$ range) (Fig. $1 \mathrm{E}$, compare exponential growth rates). Similar changes in Th distribution and mean Th $(-13.0 \pm 4.8 \%)$ were observed in the injured group that received chronic administration of the inactive stereoisomer D-NAME (Fig. 1C-E). On the contrary, chronic inhibition of either NO synthesis with L-NAME or 7-NI (data not shown) or sGC activity with ODQ preserved the Gaussian distribution of Th values and its mean $(1.8 \pm 0.5 \%,-0.8 \pm 1.5 \%$, and $0.9 \pm 0.4 \%$, respectively), although they were slightly shifted toward higher Ths (Fig. 1C-E). Together, these results suggest that decreases in recruitment Th and disorganization of the recruitment pattern in the injured motor pool are mediated by the action of NO synthesized by the induced NOS-I acting via sGC. We addressed the hypothesis that these effects are the consequence of the changes in the intrinsic membrane properties of HMNs in the following experiments.

\section{Acute versus chronic signaling through the NO/cGMP} pathway differentially regulates the excitability of HMNs

Because in vitro experiments were performed on rat pups, we confirmed that the NO-sensitive enzymatic machinery is already present at that age. Brainstem sections containing FG-labeled HMNs were further processed for sGC immunohistochemistry (Fig. 2A). As in adults, all FG-identified motoneurons were also immunoreactive for sGC (Fig. 2a2,a3).

We first tested HMN sensitivity to a short-half-life NOgenerating compound, DEA/NO, applied acutely. Superfusion of slices with DEA/NO $(10 \mu \mathrm{M})$, but not with the vehicle, for $10 \mathrm{~min}$ caused a significant and reproducible depolarization of the $V_{\mathrm{m}}$ in all HMNs tested $(3.8 \pm 0.74 \mathrm{mV})$ (Fig. $2 B)$ that was associated with a reduction in the $I_{\mathrm{Th}}(0.76 \pm 0.05$ and $0.62 \pm 0.02 \mathrm{nA}$ for control and DEA/NO, respectively) (Fig. $2 C$ ). This acute exposure had, however, no effects on $R_{\mathrm{N}}$ (Fig. $2 D$ ) or $f-I$ slope (Fig. $2 E)$. A twofold increase in DEA/NO concentration did not result in a proportional increase in its effects (Fig. $2 B-E$ ), indicating that a saturating effect was already achieved with the lower concentration. Effects of DEA/NO were blocked by ODQ (Fig. $2 B, C)$, indicating an sGC-mediated action.

Adult HMNs are characterized by an uninterrupted rhythmic 
A
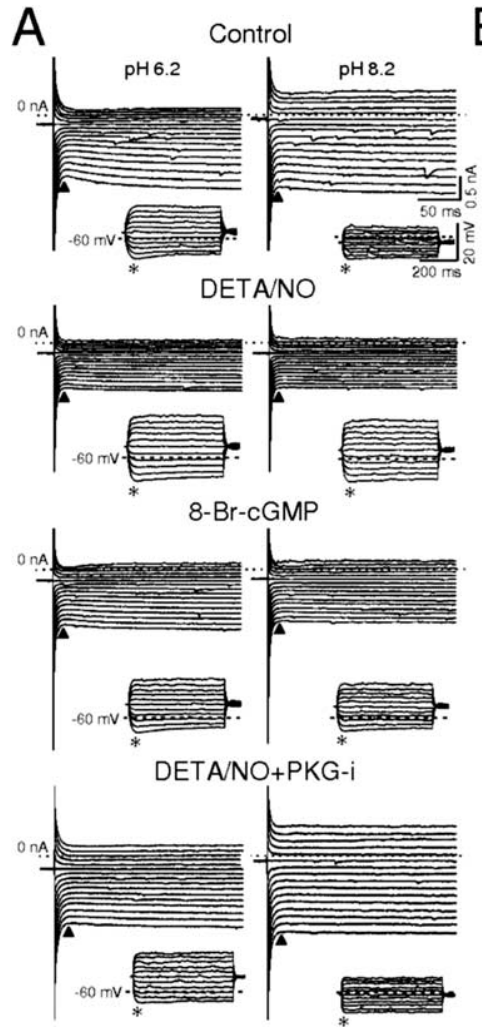

$\mathrm{B}$

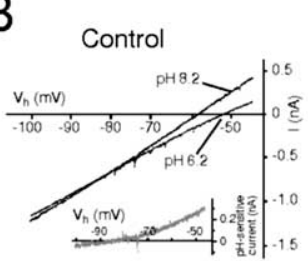

C
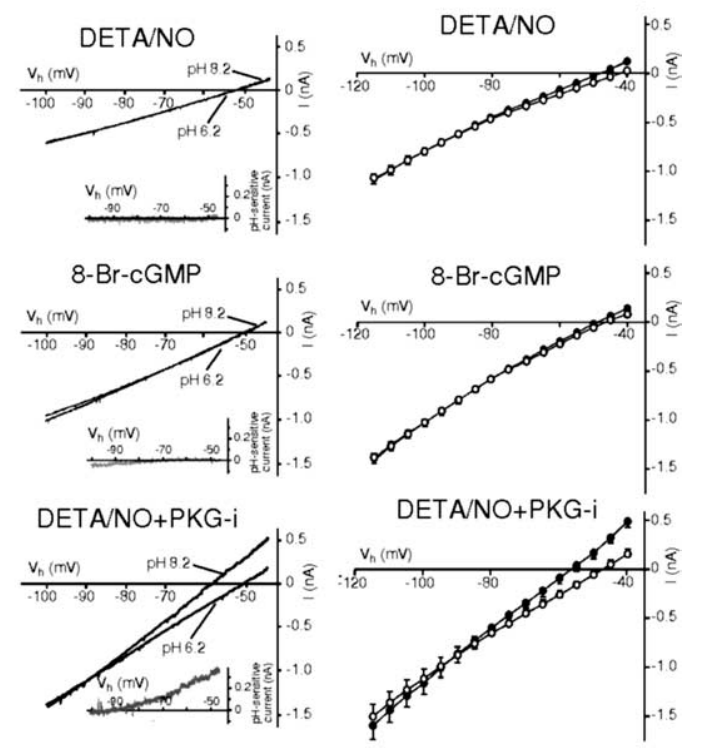

Figure 4. Sustained signaling through the NO/CGMP/PKG pathway inhibits TASK-like pH-sensitive $\mathrm{K}^{+}$conductances. $\boldsymbol{A}$, Examples of current responses to voltage-step commands (range, -115 to $-40 \mathrm{mV} ; 5 \mathrm{mV}$ increments) recorded under acidification (pH 6.2) and alkalization (pH 8.2) from representative HMNs after chronic incubations with the listed drugs. PKG-i, Rp-8-pCPTCGMPS. Instantaneous currents were measured at the end of the capacitative transient (triangles). Insets, Current-clamp recordings of the voltage responses to a series of depolarizing and hyperpolarizing current pulses ( $0.5 \mathrm{~s}$ duration, $0.04 \mathrm{nA}$ increments) from the same HMNs. Asterisks indicate the time point used to measure the peak voltage response. Dotted lines indicate either zero current or $-60 \mathrm{mV}$ in voltage-clamp and current-clamp recordings, respectively. $\boldsymbol{B}$, Currents evoked by ramping the membrane from -100 to $-45 \mathrm{mV}(40 \mathrm{mV} / \mathrm{s})$ plotted against holding potential $\left(V_{\mathrm{h}}\right)$ at both $\mathrm{pH}$ levels for the same HMNs as illustrated in $A$. Linear regression analysis $(r>0.9)$ was used to calculate $G_{\text {slope }}$ from these $I-V$ relationships. Insets, $I-V$ relationships of the $\mathrm{pH}$-sensitive current obtained by graphical subtraction of ramp currents recorded at $\mathrm{pH} 8.2$ and $\mathrm{pH} 6.2$ for each neuron. $\boldsymbol{C}$, Averaged data $(n=6-8)$ of instantaneous $I-V$ relationships in the control and chronically treated groups in response to extracellular acidification and alkalization. $G_{N}$ values were calculated as the slopes of the linear regression lines fitted to $I-V$ plots.

discharge mediated by glutamatergic inputs. Because NOS-I is upregulated in injured motoneurons, it is highly probable that this repetitive activation leads to a sustained production of NO. In an attempt to mimic this condition, slices were preincubated with a long-half-life NONOate, DETA/NO, for at least $4 \mathrm{~h}$ before the beginning of recordings. As with acute DEA/NO applications, this chronic treatment also induced $V_{\mathrm{m}}$ depolarization (5.6 \pm $0.74 \mathrm{mV}$ ) (Fig. $2 B$ ) and a marked decrease in $I_{\mathrm{Th}}(0.39 \pm 0.03 \mathrm{nA})$ (Fig. $2 C$ ). In addition, the prolonged exposure to DETA/NO caused significant increases in both $R_{\mathrm{N}}(22.8 \pm 6.7 \%)$ (Fig. $2 D$ ) and $f-I$ slope $(27.4 \pm 5.5 \%)$ (Fig. $2 E$ ). These effects were absent in slices coincubated with DETA/NO and ODQ, indicating that they were also mediated via sGC (Fig. $2 D, E$ ). To test whether changes in $R_{\mathrm{N}}$ and $f-I$ slope result from sustained depolarization, rather than from $\mathrm{NO}$ itself, slices were chronically incubated in aCSF containing high $\mathrm{K}^{+}$. This led to reductions in $I_{\mathrm{Th}}(0.29 \pm$ $0.03 \mathrm{nA})$ and membrane depolarization $(5.3 \pm 0.56 \mathrm{mV})$, which were similar to those after chronic incubation with DETA/NO. However, this treatment caused no changes in $R_{\mathrm{N}}$ and $f-I$ slope (Fig. $2 B-E$ ). Finally, to test whether the effects of NO on HMNs are direct rather than result from modification of the synaptic inputs to these neurons, some slices were preincubated and recorded in a modified aCSF with low $\mathrm{Ca}^{2+}$, high $\mathrm{Mg}^{2+}$, and a mixture of neurotransmitter receptor blockers (see Materials and Methods). Under these conditions of reduced synaptic activity, neurons also exhibited reduced $R_{\mathrm{N}}$ and higher $I_{\mathrm{Th}}$ and $f-I$ slopes (Fig. $2 B-$ $E)$. In this environment of reduced synaptic activity, chronic effects of DETA/NO were also similar to those found under normal conditions of spontaneous synaptic activity (Fig. $2 B-E$ ). Likewise, all of the modulatory effects of $\mathrm{NO}$ were essentially mimicked by the permeant cGMP-analog 8-Br-cGMP (Fig. $2 B-E$ ) and, therefore, most probably cGMP mediated.

\section{Persistent activation of the NO/cGMP/ PKG cascade inhibits TASK-like $\mathbf{p H}$ - sensitive $\mathrm{K}^{+}$conductances}

We next investigated the possibility that the sustained exposure to $\mathrm{NO}$ exerted its effects via inhibition of TASK $\mathrm{pH}$-sensitive resting $\mathrm{K}^{+}$conductances. Because these channels are highly expressed in motor nuclei (Talley et al., 2000; Berg et al., 2004), we tested the effects of $\mathrm{pH}$ on HMNs of P6-P9 rats. Voltage-clamp recordings from HMNs held at $-65 \mathrm{mV}$ in the continuing presence of TTX showed that acidification of the aCSF resulted in an inward shift in $I_{\text {holding, }}$, whereas alkalization induced a change in the outward direction (Fig. 3A). In current-clamp mode, perfusion with an acidic aCSF increased the excitability of HMNs. Figure $3 B$ illustrates a response of one HMN to a positive current pulse under alkaline $(\mathrm{pH} 8.2)$ and acidic ( $\mathrm{pH}$ 6.2) conditions and demonstrates a greatly increased excitability at acidic $\mathrm{pH}$. Thus, in vitro recordings demonstrate functional characteristics consistent with expression of TASK-like $\mathrm{pH}$-sensitive $\mathrm{K}^{+}$conductances on neonatal HMNs. Given the similarity between the effects of acidification and chronic influence of $\mathrm{NO}$ on motoneuron excitability, we postulated that both manipulations may target the same ion channels. Closure of TASK channels is also controlled by a number of transmitters and neuromodulators such as TRH (Talley et al., 2000, 2003; Chen et al., 2006). Under voltage clamp (holding potential, $-65 \mathrm{mV}$ ), TRH induced an inward shift of the $I_{\text {holding }}$ in all HMNs tested from control slices $(-0.348 \pm 0.67 \mathrm{nA}$; $n=5)$. Interestingly, chronic treatment of slices with DETA/NO almost fully inhibited the TRH-induced response $(-75.2 \pm$ $6.7 \% ; n=5$ ) (Fig. 3C), which suggested a contribution of TASK channels as possible effectors for the chronic action of $\mathrm{NO}$ on motoneuron excitability.

To investigate in more detail the role of TASK channels in mediating such effects, we next compared the $\mathrm{pH}$ sensitivity of HMNs recorded from control and chronically treated slices. $I-V$ relationships were constructed using both voltage-step and voltage-ramp protocols (Fig. 4) (see Materials and Methods). In control HMNs, current responses to voltage steps in alkalinized solution ( $\mathrm{pH}$ 8.2) were much larger than in acidified $(\mathrm{pH}$ 6.2) solution, indicating a larger $G_{\mathrm{N}}$ at the higher $\mathrm{pH}$ value (Fig. $4 A$ ). Similarly, the slope conductance $G_{\text {slope }}$, obtained from the slope 

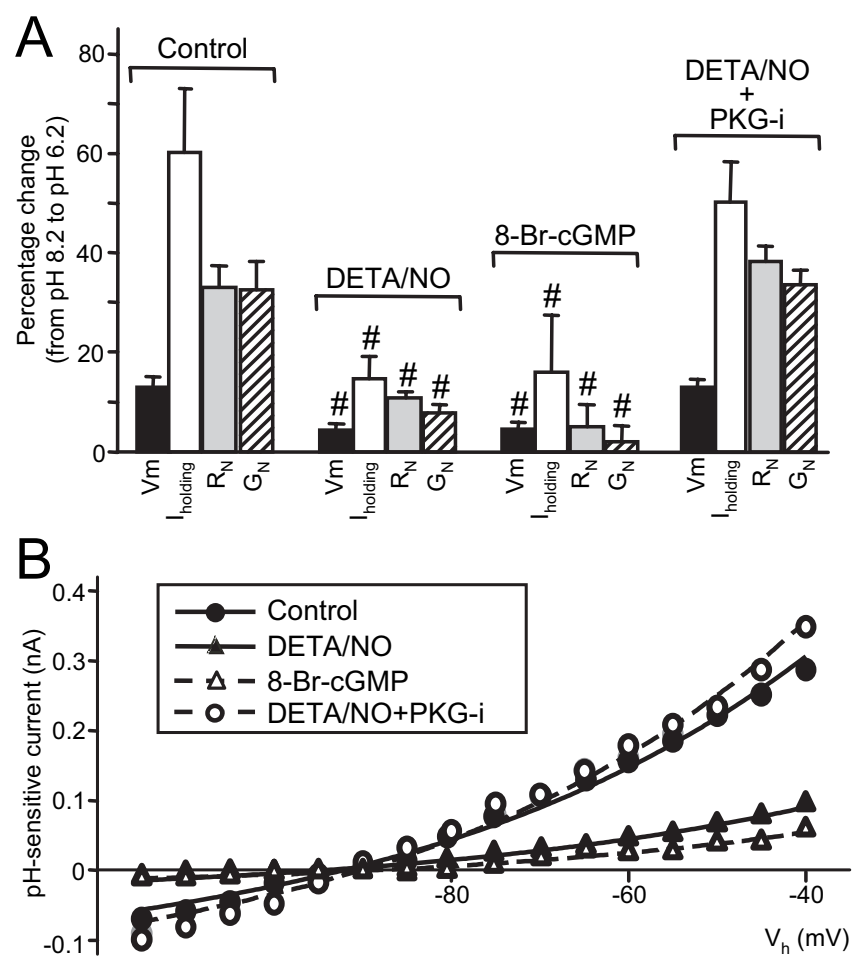

Figure 5. Effects of modulators of the NO/CGMP/PKG pathway on the pH sensitivity of hypoglossal motoneurons. $A$, Summary of changes in $V_{\mathrm{m}^{\prime}} I_{\text {holding, }}, R_{\mathrm{N}^{\prime}}$ and $G_{\mathrm{N}}$ induced by acidification from a basal alkaline $\mathrm{pH}$ for each listed treatment group. ${ }^{p} p<0.05$; one-way ANOVA; post hoc Tukey's test with respect to the control group. $B$, Averaged $I-V$ relationships of the $\mathrm{pH}$ sensitive current component obtained after subtracting mean instantaneous leak currents at pH 6.2 from those at pH 8.2 in Figure 4C. In all cases, these data were well fitted $(r>0.9)$ with the Goldman-Hodgkin-Katz equation (solid lines) and currents reversed between -90 and $-100 \mathrm{mV}$, which was close to the reversal potential predicted theoretically by the Nerst equation for $\mathrm{K}^{+}$.

of the $I-V$ curves generated by the ramp protocol, was attenuated at pH 6.2 and increased at pH 8.2 (Fig. $4 B$ ). Therefore, changing the external pH from 8.2 to 6.2 reversibly induced increases in $R_{\mathrm{N}}$ and significant reductions in $G_{\mathrm{N}}$ and $G_{\text {slope }}$ (Fig. 4). Modulation of TASK-like $\mathrm{pH}$-sensitive $\mathrm{K}^{+}$currents was almost entirely suppressed after preincubations with DETA/NO or 8-Br-cGMP (Fig. 4). Accordingly, the $\mathrm{pH}$-sensitive component of the whole-cell current calculated by subtracting ramp traces at $\mathrm{pH} 6.2$ from those at $\mathrm{pH} 8.2$ was significantly reduced compared with controls (Fig. $4 B$, insets). This inhibitory effect was prevented, however, when DETA/NO and Rp-8-pCPT-cGMPS, a potent cellpermeable inhibitor of $\mathrm{PKG}$, were coadded to the incubation medium (Fig. $4 A, B$ ). Averaged $I-V$ plots generated by the voltage-step protocol at both $\mathrm{pH}$ values are illustrated in Figure $4 C$ for each treatment. Mean $G_{\mathrm{N}}$ ratios at $\mathrm{pH} 6.2 / \mathrm{pH} 8.2$ were $16.7 / 26.7,14.4 / 15.5,19.2 / 19.7$, and 23.3/31.2 nS for the control, DETA/NO-, 8-Br-cGMP-, and DETA/NO plus Rp-8-pCPTcGMPS-treated groups, respectively, which indicates that the "high-conductance" status at $\mathrm{pH} 8.2$ was more profoundly affected by the treatments used to stimulate the NO/cGMP pathway. A summary of the $\mathrm{HMN}$ responsiveness to $\mathrm{pH}$ (reflected as percentage change for several membrane parameters in response to $\mathrm{pH}$ changes) exhibited by HMNs under different drug treatments is depicted in Figure $5 \mathrm{~A}$. The $\mathrm{pH}$-sensitive current in each group was obtained by subtracting the currents recorded at $\mathrm{pH}$ 8.2 from those obtained at $\mathrm{pH} 6.2$ using the voltage-step protocol (Fig. $5 B$ ). In all four cases, the subtracted currents reversed close to the reversal potential calculated for $\mathrm{K}^{+}$ions (approximately
$-90 \mathrm{mV}$ ) and were well fitted by the Goldman-Hodking-Katz constant-field equation $(r>0.98)$ (Fig. $5 B)$, thus displaying properties of an outward rectifier $\mathrm{K}^{+}$conductance. These currents were almost completely inhibited after persistent activation of the NO/cGMP pathway, whereas the inhibition of PKG completely abolished this blocking effect (Fig. 5B). Together, these results indicated that the persistent action of the NO/cGMP/PKG pathway increases $\mathrm{HMN}$ excitability through a specific inhibitory action on TASK-like $\mathrm{pH}$-sensitive leak $\mathrm{K}^{+}$conductances.

\section{Acute exposure to NO or cGMP increases a net inward current without changing the overall input conductance} Because chronic activation of the NO/cGMP cascade caused more profound changes in membrane excitability parameters than short-term exposure (Fig. $2 B-D$ ), we investigated whether acute NO/cGMP-induced depolarizations were mediated through a different subset of conductances. Application of DEA/NO or 8-Br-cGMP for $10 \mathrm{~min}$ also evoked pronounced inward shifts in the $I_{\text {holding }}$ relative to control preexposure values (difference, $-133.1 \pm 25.9 \mathrm{pA}$ and $-136.6 \pm 14.2 \mathrm{pA}$, respectively), which reversed entirely after $10 \mathrm{~min}$ washout. Likewise, the mean $I_{\text {holding }}$ of the HMN pool treated chronically with DETA/NO shifted inward (difference, $-91.0 \pm 18.6 \mathrm{pA}$ ) relative to that measured in the control group. Thus, an inward drift in the $I_{\text {holding }}$ is induced by either chronic DETA/NO or acute DEA/NO application, which accounts for $V_{\mathrm{m}}$ depolarization in both cases. Nevertheless, the absence of changes in $R_{\mathrm{N}}$ during acute DEA/NO or 8-Br-cGMP treatments and the presence of this effect after chronic exposure to DETA/NO or 8-Br-cGMP suggests that $\mathrm{NO}$ via cGMP could be acting on different subsets of ionic channels depending on the time of exposure. Acute DEA/NO application had no effect on the slope of the $I-V$ curves even though it depolarized HMNs and caused a robust shift in the $I_{\text {holding }}$ (Fig. 6A,B). Such "short-term" depolarizing action was preserved even in the presence of TTX and a mixture of synaptic blockers (difference, $3.6 \pm 0.5 \mathrm{mV}$ ) without significantly affecting $R_{\mathrm{N}}(4.7 \pm 6.8 \%$ with respect to the control), which excludes the possibility that any change in $R_{\mathrm{N}}$ could be obscured by a parallel modification in synaptic inputs. Interestingly, acute infusion of DEA/NO resulted in $V_{\mathrm{m}}$ depolarization that was larger than that induced by acidification to $\mathrm{pH} 6.2$ (Fig. 6C), a pH value known to block almost completely TASK-like acid-sensitive conductances (Berg et al., 2004). Furthermore, when DEA/NO was applied after bath acidification, it induced an additional depolarization (Fig. 6C). In summary, whereas cells chronically treated with DETA/NO $(n=28)$ showed changes in $V_{\mathrm{m}}, I_{\text {holding, }}, R_{\mathrm{N}}$, and $G_{\mathrm{N}}$ with respect to the control pool $(n=27)$, short-term exposure to either DEA/NO or 8-Br-cGMP modified only $V_{\mathrm{m}}$ and $I_{\text {holding }}$ (Fig. 6D). These experiments suggest that the NO/cGMP pathway acts via two different mechanisms regulating $\mathrm{HMN}$ excitability depending on the longevity of its action (Fig. 7D). Short-term action of the NO/cGMP cascade could involve either a TASK-independent conductance or a combination of effects on different subtypes of resting conductances without a net impact on the overall $R_{\mathrm{N}}$. On the contrary, chronic effects involve the reduction of resting TASK-like $\mathrm{K}^{+}$conductances via cGMP synthesis and PKG activation, which reduces membrane conductance, depolarizes HMNs, and increases their excitability.

Inhibition of TASK conductances underlies increases in excitability of injured HMNs

In light of the previously described results, we proceeded to ask whether XIIth nerve injury upregulated intrinsic excitability of 
A
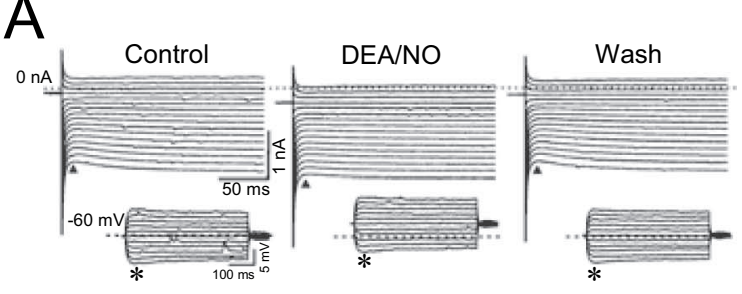

B

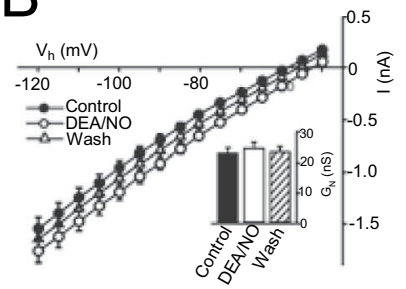

$\mathcal{C}$

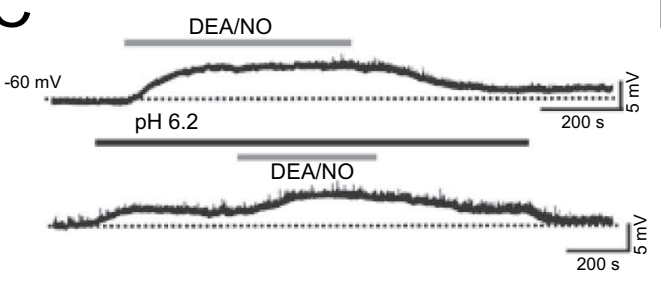

D

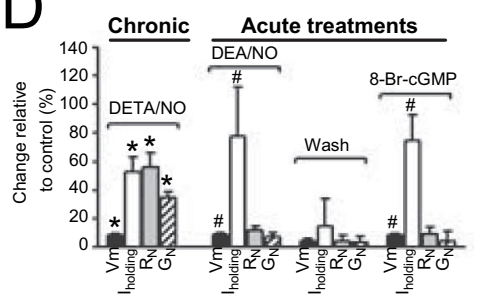

Figure 6. Short-term exposure to NO depolarizes hypoglossal motoneurons without changing the overall resting conductance. $A$, Current traces obtained from a motoneuron in response to voltage steps in control aCSF, at the end of a 10 min incubation with DEA/NO and again after 10 min of washout. Insets, Voltage responses to current injections recorded from the same HMN in the course of application of DEA/NO. Dotted lines, asterisks, and triangles represent the same as in Figure $4 A$. B, Averaged $I-V$ relationships $(n=9)$ of instantaneous current responses in control aCSF, in the presence of DEA/NO and after 10 min washout. Inset, Mean $G_{N}$ from HMNs before and during DEA/NO infusion and after washout. C, Current-clamp recordings from an HMN showing the effects of DEA/NO on $V_{m}$ in control aCSF (top trace) or after steady-state change in $V_{m}$ caused by extracellular acidification. $D$, Summary of changes (expressed as absolute percentage variation) in $V_{m}, R_{N}, I_{\text {holding, }}$ and $G_{N}$ induced by chronic incubations with DETA/NO and acute treatments with DEA/NO or 8-Br-cGMP $(n=7)$. ${ }^{*} p<0.05$; one-way ANOVA; post hoc Tukey's test relative to the control group. ${ }^{\#} p<0.05$; one-way ANOVA for repeated measurements; post hoc Tukey's test relative to the preexposure control condition.

HMNs and, if so, whether this change was directly linked to the inhibition of TASK-like conductances. To that end, we recorded HMNs in slices obtained from 6- to 8-d-old rat pups after XIIth nerve crush at $\mathrm{P} 3$ and analyzed their sensitivity to $\mathrm{pH}$ variations (Fig. 7A,B). Whole-cell recordings in the presence of TTX showed that injured motoneurons had very high $R_{\mathrm{N}}(108.5 \pm$ 10.7 M $\Omega$ ). This represented an increase of $153.3 \%$ over the averaged $R_{\mathrm{N}}$ calculated for the control group. In parallel with this observation, we found a considerable reduction in the responsiveness of lesioned HMNs to $\mathrm{pH}$ changes (Fig. $7 A, B$ ). Therefore, we can conclude that nerve crush induces a reduction in TASKlike $\mathrm{pH}$-sensitive $\mathrm{K}^{+}$conductances in motoneurons comparable with that induced by chronic incubations with $\mathrm{NO}$ donors in intact motoneurons.

Given that changes in excitability induced by a sustained synthesis of NO seem to represent a long-term mechanism, we could expect that its effects should be slow in onset and reversal. Electroneurographic recordings in adult lesioned animals at $7 \mathrm{~d}$ after injury were used to follow the time course of the ratio between the injured and intact whole-nerve activities just after administering D-NAME, L-NAME, or 7-NI. As previously reported by us, nerve activity on the lesioned side was significantly reduced relative to the intact side (Fig. 7C,D, top traces), an effect that correlated well with the loss of afferent inputs on motoneurons (GonzálezForero et al., 2004b). Systemic administration of D-NAME did not alter this ratio over the course of a $7 \mathrm{~h}$ experiment (Fig. 7C,E, black circles). On the contrary, the NOS inhibitor L-NAME unbalanced even more this ratio, inducing a progressive decline that reached statistical significance at $2 \mathrm{~h}$ after injection, peaked at $3 \mathrm{~h}$, and then was maintained for the next $4 \mathrm{~h}$ period (Fig. $7 \mathrm{D}$, E, open circles). Similar dynamics was observed using 7-NI (data not shown). Thus, at $5 \mathrm{~h}$ after drug administration, nerve activity on the lesioned side was significantly reduced relative to the control side in L-NAME- $(-26.0 \pm 8.0 \%)$ and 7-NI-treated animals $(-19.3 \pm 3.6 \%)$, whereas it remained unchanged in the D-NAME-treated group $(-0.2 \pm 9.6 \%)$. These results strongly support the notion that NO operates in adult injured motoneurons and is required to maintain an enhanced basal activity.

\section{Discussion}

This study provides the first account of a mechanism that could be an important component in a complex physiopathological response to nerve injury and possibly some neurodegenerative disorders. We provide strong evidence that in HMNs, persistent, but not acute, activation of $\mathrm{NO} /$ cGMP pathway leads to a pronounced enhancement of neuronal excitability through a PKG-dependent inhibition of TASK-like $\mathrm{K}^{+}$currents. In neurons lacking NOS-I but innervated by nitrergic afferents, this regulatory mechanism could serve to tightly couple postsynaptic excitability to synaptic use. Likewise, it could also provide a mean to increase excitability of membrane areas adjacent to repeatedly stimulated glutamatergic postsynaptic densities on NOS-I-expressing neurons, in which $\mathrm{Ca}^{2+}$ influx and NO production are spatially and functionally coupled (Garthwaite et al., 1988; Watanabe et al., 2003). This same link between postsynaptic activation, NO production, and increase of excitability might render nitrergic neurons highly susceptible to excitotoxic damage and death in the course of neurodegenerative and traumatic brain diseases (Thorns et al., 1998; Moreno-López and González-Forero, 2006).

Typically, axotomized motoneurons exhibit features of an enhanced excitability, (González-Forero et al., 2004a) which are accompanied by de novo expression of NOS-I (Yu, 1997; Sunico et al., 2005; Moreno-López and González-Forero, 2006). Recruitment order in a motor pool is primarily determined by intrinsic membrane properties, although synaptic input organization and the patterns of afferent activity could eventually modify Th range or recruitment gain (Gustafsson and Pinter, 1985; Heckman and Binder, 1993; Cope and Sokoloff, 1999). Because axonal injury induces predominantly the loss of excitatory synaptic terminals on adult HMNs (Sumner, 1975) and also a pronounced increase in $R_{\mathrm{N}}$ of both neonatal and adult HMNs (Moreno-López and González-Forero, 2006), we can reasonably assume that changes in the recruitment pattern arise from this enhanced intrinsic excitability and not from the altered synaptic drive, which according to its own sign would be expected to result in an opposed effect. The increased incidence of low-Th units in the lesioned pool was prevented by chronic inhibition of NOS-I or sGC in vivo. These data, along with the lack of expression of the inducible isoform of NOS (NOS-II) after injury (Sunico et al., 2005), and the absence of effects of L-NAME in intact animals, indicate that the changes in recruitment distribution are mediated by the de novo production of $\mathrm{NO}$ in damaged motoneurons acting via an autocrine signaling loop that enhances cGMP synthesis and intrinsic excitability.

This idea receives support from previous studies demonstrat- 
ing that bath application of NO increases intrinsic neuronal excitability in vitro (Bains and Ferguson, 1997; Shaw et al., 1999; Yang and Hatton, 1999; Abudara et al., 2002; Pose et al., 2003). Although experimental approaches using exogenous NO application do not exactly mimic the transient and discrete synthesis of NO by NOS-I-expressing neurons in response to synaptic stimulation, they confirm that some membrane properties determining intrinsic excitability are modulated by NO. The production of NO is coupled to synaptic activity via NMDA receptors and $\mathrm{Ca}^{2+} /$ calmodulin-dependent NOS-I activation (Garthwaite et al., 1988). NO released as a result of this action might modulate intrinsic excitability through PKG activation and/or S-nitrosylation of multiple channel proteins (Ahern et al., 2002). In experiments designed to reproduce such short-term NO actions, several studies revealed reversible changes in excitability consisting of $V_{\mathrm{m}}$ depolarization and decreases in $I_{\mathrm{Th}}$, without parallel alterations in $R_{\mathrm{N}}$ (Bains and Ferguson, 1997; Shaw et al., 1999; Yang and Hatton, 1999; Abudara et al., 2002; Pose et al., 2003; Wang et al., 2006). However, even in the lesioned state, HMNs are characterized by an uninterrupted inspiratory activity mediated by glutamatergic inputs (Wang et al., 2002; González-Forero et al., 2004b). It could be expected that, under these conditions, NOS-I will be persistently activated to produce NO, leading perhaps to even more profound alterations in neuronal excitability. In agreement with this hypothesis, chronic incubations with a NONOate induced an additional increase in $R_{\mathrm{N}}$ and $f-I$ slope in a synaptic-independent way. Similar conclusions could be reached from previous works in cerebellar and striatal neurons, in which NOS or sGC inhibitors caused hyperpolarization and decreases in $R_{\mathrm{N}}$ (Wall, 2003; West and Grace, 2004). It is unlikely that additional effects of the chronic treatment on neuron excitability could be a consequence of the differences in $\mathrm{NO}$ concentrations released by different NONOates in this study, because a fourfold increase in DETA/NO concentration, relative to the one used here, had no effects or even reduced $R_{\mathrm{N}}$ in sensory and motor neurons during acute exposures (Abudara et al., 2002; Pose et al., 2003).

It is logical to expect that ionic channels exerting a powerful control over membrane excitability are likely to be the downstream targets for the NO/cGMP signaling. Resting voltage-independent leak $\mathrm{K}^{+}$ conductances are determinants for setting intrinsic excitability. Motoneurons ex-
A 4 days after crushing

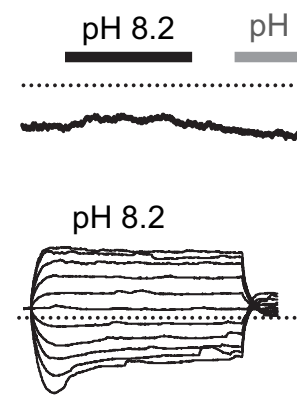
H 6.2
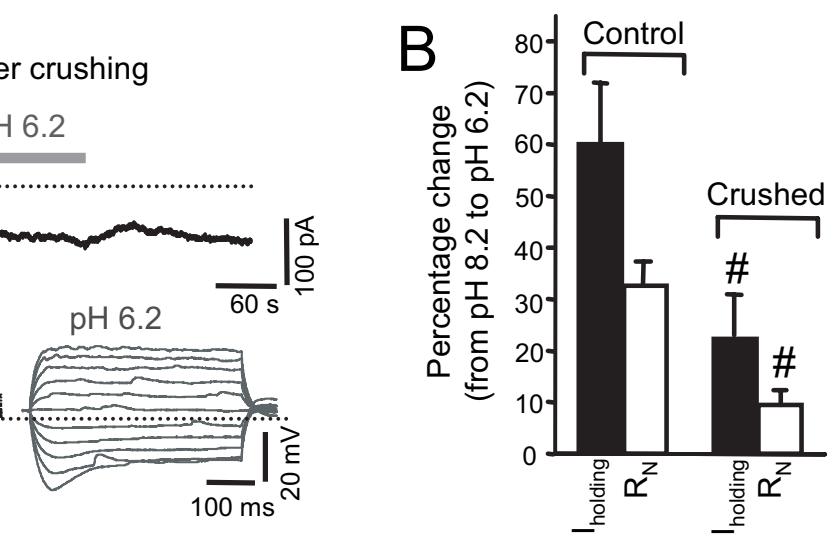

C $1 \mathrm{~min}$ before D-NAME injection

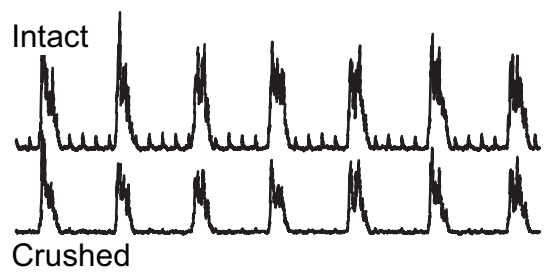

$5 \mathrm{~h}$ after D-NAME injection

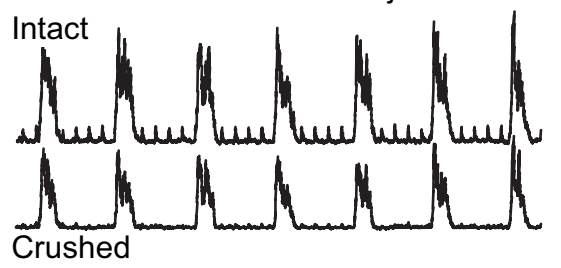

Intact

Intact

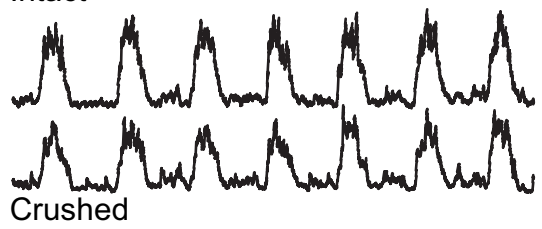

$5 \mathrm{~h}$ after L-NAME injection

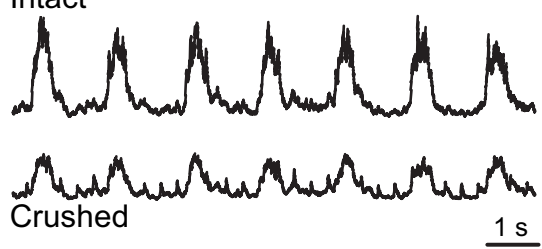

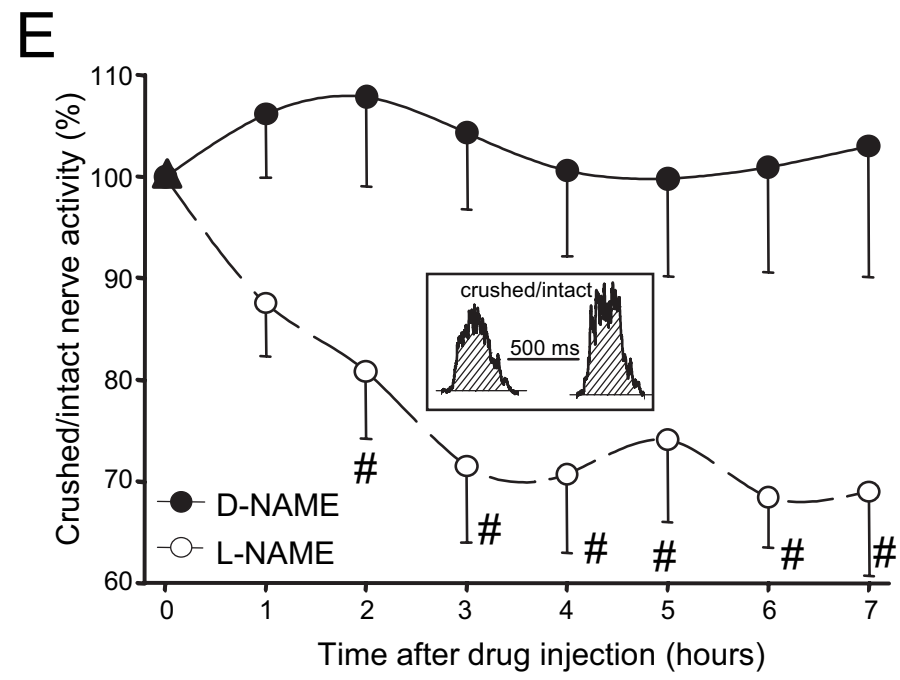

Figure 7. Peripheral nerve injury downregulates TASK channel function and increases the basal activity of injured motoneurons. $A$, Top, Time series illustrating changes in $/$ holding in response to variations in extracellular pH for a P7 HMN held at $-65 \mathrm{mV}$ and recorded $4 \mathrm{~d}$ after ipsilateral XIlth nerve crushing. Bottom, Current-clamp recordings of the voltage responses to a series of depolarizing and hyperpolarizing current pulses ( $0.5 \mathrm{~s}$ duration, $0.04 \mathrm{nA}$ increments) from the same $H M N$ at the indicated extracellular $\mathrm{pH}$ values. $\boldsymbol{B}$, Summary of changes in $I_{\text {holding }}$ and $R_{\mathrm{N}}$ induced by acidification from a basal alkaline $\mathrm{pH}$ in intact (control) and crushed P6-P9 HMNs $(n=5)$. Control data (illustrated here for comparison) are the same as those shown in Figure $5 A .{ }^{\#} p<0.05$; one-way ANOVA; post hoc Tukey's test with respect to the control group. C, D, Integrated bilateral recordings from XIlth nerves in adult animals at $7 \mathrm{~d}$ after lesion obtained $1 \mathrm{~min}$ before (top traces) and $5 \mathrm{~h}$ after (bottom traces) administration of the indicated drugs. $\boldsymbol{E}$, Time course of the ratio between the crushed and intact whole-nerve activities recorded from adult animals at $7 \mathrm{~d}$ after lesion after administration (at time 0 ) of D-NAME or L-NAME. Data were expressed as percentage of the measurements taken 5 min before drug administration (100\%; triangle). Inset, The area contained within the integral of each inspiratory burst was used to construct the ratio of activities for the crushed/intact sides. $n=5$ for D-NAME and $n=3$ for L-NAME. ${ }^{\#}<0.05$; two-way ANOVA; post hoc Tukey's test relative to both the preadministration value in the same group and the $D$-NAME-treated group. 
press particularly high levels of TASK pH-sensitive channels, which provide a substantial component of their background $\mathrm{K}^{+}$ current (Talley et al., 2001; Bayliss et al., 2003; Berg et al., 2004). Inhibition of TASK-like conductances leads to membrane depolarization and increases in $R_{\mathrm{N}}$ and intrinsic excitability (Talley et al., 2000, 2003; Bayliss et al., 2003). In this way, in vitro recordings from HMNs subjected to prolonged exposures to DETA/NO confirmed that the main action of $\mathrm{NO}$ involves inhibition of TASK-like conductances. These results, along with changes in the recruitment pattern of the lesioned pool, still leave open the possibility that a similar modulatory action by endogenous NO may be exerted in HMNs after axonal injury. Evidence for this hypothesis comes from three findings: (1) $\mathrm{pH}$ sensitivity of neonatal HMNs was greatly reduced after nerve injury; (2) chronic administration of NOS-I or sGC inhibitors prevented reduction of recruitment Ths induced by nerve crushing in the lesioned HN; and (3) administration of NOS-I inhibitors to adult animals at $7 \mathrm{~d}$ after nerve crushing produces a long-latency decrease $(>2 \mathrm{~h})$ in the ratio between the injured and intact whole-nerve activities, indicating the activation of an NO-induced long-term mechanism that maintains an increased basal activity in injured HMNs.

Continuous, but not transient, presence of a NONOate in the extracellular solution shifted inward the $I_{\text {holding }}$ and increased $R_{\mathrm{N}}$ of HMNs. The decrease in membrane conductance by prolonged NO exposures was associated with a marked loss of sensitivity to $\mathrm{pH}$ variations and inhibition of a background current that displayed features of TASK-like conductances (i.e., reversal close to $E_{\mathrm{K}}{ }^{+}$, outward rectification, and modulation by proton concentrations) (Talley et al., 2000; Berg et al., 2004). This almost complete blockade of TASK-like $\mathrm{K}^{+}$currents was mimicked by 8 -BrcGMP and prevented by a PKG inhibitor, indicating the involvement of the $\mathrm{NO} / \mathrm{cGMP} / \mathrm{PKG}$ cascade. On the contrary, acute NO or cGMP incubations evoked similar inward shifts in the $I_{\text {holding }}$ but lacked effects on background conductances. NO action was independent of synaptic activity and therefore not contaminated by possible changes in synaptic function. Subsequently, it is reasonable to assume that the acute NO/cGMP effects could reflect an action on either a TASK-independent conductance or a combination of background conductances that compensate each other to avoid a net variation in the $R_{\mathrm{N}}$. In line with this idea, depolarization induced by acute NO incubations occurred even in an acidified extracellular solution, which almost completely inhibits TASK-mediated conductances (Berg et al., 2004). This leads us to the conclusion that the main action of acute $\mathrm{NO}$ on $I_{\text {holding }}$ and $V_{\mathrm{m}}$ must be associated with effects other than modulation of TASK-like conductances.

Neurotransmitter modulation of TASK channels (Talley et al., 2000) occurs via direct association of the activated G $\alpha$ q subunit with the channel (Chen et al., 2006). Such direct interaction would account for the fast neuromodulatory actions on this conductance but disagree with the slower regulation by NO. It is likely that NO/cGMP/PKG-mediated modulation of TASK-like conductances occurs through mechanisms other than simple PKG-mediated channel phosphorylation, perhaps involving additional signaling pathways, regulation of gene or protein expression, and/or trafficking of the channels (Sauzeau et al., 2003; Renigunta et al., 2006).

NOS-I upregulation and elevated levels of NO have been causally associated with neurodegeneration in the course of a broad range of neurological disorders (Lipton, 2004; Moreno-López and González-Forero, 2006). For instance, in animal models of ALS, NO causes hyperexcitability and sensitizes motoneurons to death (Raoul et al., 2002; Kuo et al., 2004, 2005), whereas its inhibition prevents experimentally induced parkinsonism (Hantraye et al., 1996; Itzhak and Ali, 1996; Moreno-López and González-Forero, 2006). Likewise, NOS-I-expressing neurons in the entorhinal cortex and hippocampus are highly vulnerable to neurodegeneration in the progression of the Alzheimer's disease (Thorns et al., 1998). Therefore, although a relationship between NOS-I expression and susceptibility to neuronal death seems evident, the cellular mechanisms underlying such deleterious processes remain elusive. Interestingly, differences in the expression level and pattern of TASK channels has been also related to a variable susceptibility to ischemic damage and apoptotic cell death (Patel and Lazdunski, 2004; Taverna et al., 2005). Our results provide a way to integrate these facts and propose a hypothesis whereby TASK channel inhibition via persistent autocrine activation of the NO/cGMP/PKG cascade could sensitize NOSexpressing neurons to excitotoxic damage in brain neurodegenerative processes via a sustained increase in their excitability.

\section{References}

Abudara V, Alvarez AF, Chase MH, Morales FR (2002) Nitric oxide as an anterograde neurotransmitter in the trigeminal motor pool. J Neurophysiol 88:497-506.

Ahern GP, Klyachko VA, Jackson MB (2002) cGMP and S-nitrosylation: two routes for modulation of neuronal excitability by NO. Trends Neurosci 25:510-517.

Bains JS, Ferguson AV (1997) Nitric oxide depolarizes type II paraventricular nucleus neurons in vitro. Neuroscience 79:149-159.

Bayliss DA, Sirois JE, Talley EM (2003) The TASK family: two-pore domain background $\mathrm{K}+$ channels. Mol Interv 3:205-219.

Berg AP, Talley EM, Manger JP, Bayliss DA (2004) Motoneurons express heteromeric TWIK-related acid-sensitive $\mathrm{K}^{+}$(TASK) channels containing TASK-1 (KCNK3) and TASK-3 (KCNK9) subunits. J Neurosci 24:6693-6702.

Chen X, Talley EM, Patel N, Gomis A, McIntire WE, Dong B, Viana F, Garrison JC, Bayliss DA (2006) Inhibition of a background potassium channel by Gq protein $\alpha$-subunits. Proc Natl Acad Sci USA 103:3422-3427.

Cope TC, Sokoloff AJ (1999) Orderly recruitment among motoneurons supplying different muscles. J Physiol (Paris) 93:81-85.

Garthwaite J, Charles SL, Chess-Williams R (1988) Endothelium-derived relaxing factor release on activation of NMDA receptors suggests role as intercellular messenger in the brain. Nature 336:385-388.

González-Forero D, Benítez-Temiño B, de la Cruz RR, Pastor AM (2004a) Functional recovery in the peripheral and central nervous system after injury. In: Brain damage and repair. From molecular research to clinical therapy (Herdegen T, Delgado-García JM, eds), pp 285-305. Durdrecht, The Netherlands: Kluwer.

González-Forero D, Portillo F, Sunico CR, Moreno-López B (2004b) Nerve injury reduces responses of hypoglossal motoneurones to baseline and chemoreceptor-modulated inspiratory drive in the adult rat. J Physiol (Lond) 557:991-1011.

Gustafsson B, Pinter MJ (1985) On factors determining orderly recruitment of motor units: a role for intrinsic membrane intrinsic properties. Trends Neurosci 8:431-433.

Hantraye P, Brouillet E, Ferrante R, Palfi S, Dolan R, Matthews RT, Beal MF (1996) Inhibition of neuronal nitric oxide synthase prevents MPTPinduced parkinsonism in baboons. Nat Med 2:1017-1021.

Heckman CJ, Binder MD (1993) Computer simulations of motoneuron firing rate modulation. J Neurophysiol 69:1005-1008.

Hwang JC, Bartlett Jr D, St John WM (1983) Characterization of respiratory-modulated activities of hypoglossal motoneurons. J Appl Physiol 55:793-798.

Itzhak Y, Ali SF (1996) The neuronal nitric oxide synthase inhibitor, 7-nitroindazole, protects against methamphetamine-induced neurotoxicity in vivo. J Neurochem 67:1770-1773.

Kuo JJ, Schonewille M, Siddique T, Schults AN, Fu R, Bar PR, Anelli R, Heckman CJ, Kroese AB (2004) Hyperexcitability of cultured spinal motoneurons from presymptomatic ALS mice. J Neurophysiol 91:571-575.

Kuo JJ, Siddique T, Fu R, Heckman CJ (2005) Increased persistent $\mathrm{Na}(+$ ) 
current and its effect on excitability in motoneurones cultured from mutant SOD1 mice. J Physiol (Lond) 563:843-854.

Lipton SA (2004) Failures and successes of NMDA receptor antagonists: molecular basis for the use of open-channel blockers like memantine in the treatment of acute and chronic neurologic insults. NeuroRx 1:101-110.

McCormick DA, Bal T (1997) Sleep and arousal: thalamocortical mechanisms. Annu Rev Neurosci 20:185-215.

Moreno-López B, González-Forero D (2006) Nitric oxide and synaptic dynamics in the adult brain: physiopathological aspects. Rev Neurosci 17:309-357.

Moreno-López B, Romero-Grimaldi C, Noval JA, Murillo-Carretero M, Matarredona ER, Estrada C (2004) Nitric oxide is a physiological inhibitor of neurogenesis in the adult mouse subventricular zone and olfactory bulb. J Neurosci 24:85-95.

Patel AJ, Lazdunski M (2004) The 2P-domain $\mathrm{K}^{+}$channels: role in apoptosis and tumorigenesis. Pflügers Arch 448:261-273.

Pose I, Sampogna S, Chare MH, Morales FR (2003) Mesencephalic trigeminal neurons are innervated by nitric oxide synthase-containing fibers and respond to nitric oxide. Brain Res 960:81-89.

Raoul C, Estevez AG, Nishimune H, Cleveland DW, deLapeyriere O, Henderson CE, Haase G, Pettmann B (2002) Motoneuron death triggered by a specific pathway downstream of Fas potentiation by ALS-linked SOD1 mutations. Neuron 35:1067-1083.

Renigunta V, Yuan H, Zuzarte M, Rinne S, Koch A, Wischmeyer E, Schlichthorl G, Gao Y, Karschin A, Jacob R, Schwappach B, Daut J, PreisigMuller R (2006) The retention factor p11 confers an endoplasmic reticulum-localization signal to the potassium channel TASK-1. Traffic $7: 168-181$.

Sauzeau V, Rolli-Derkinderen M, Marionneau C, Loirand G, Pacaud P (2003) RhoA expression is controlled by nitric oxide through cGMPdependent protein kinase activation. J Biol Chem 278:9472-9480.

Shaw PJ, Charles SL, Salt TE (1999) Actions of 8-bromo-cyclic-GMP on neurones in the rat thalamus in vivo and in vitro. Brain Res 833:272-277.

Sumner BEH (1975) A quantitative analysis of boutons with different types of synapse in normal and injured hypoglossal nuclei. Exp Neurol 49:406-417.

Sunico CR, Portillo F, González-Forero D, Moreno-López B (2005) Nitricoxide-directed synaptic remodeling in the adult mammal CNS. J Neurosci $25: 1448-1458$.
Talley EM, Lei Q, Sirois JE, Bayliss DA (2000) TASK-1, a two-pore domain $\mathrm{K}+$ channel, is modulated by multiple neurotransmitters in motoneurons. Neuron 25:399-410.

Talley EM, Solorzano G, Lei Q, Kim D, Bayliss DA (2001) CNS distribution of members of the two-pore-domain (KCNK) potassium channel family. J Neurosci 21:7491-7505.

Talley EM, Sirois JE, Lei Q, Bayliss DA (2003) Two-pore-domain (KCNK) potassium channels: dynamic roles in neuronal function. Neuroscientist 9:46-56.

Taverna S, Tkatch T, Metz AE, Martina M (2005) Differential expression of TASK channels between horizontal interneurons and pyramidal cells of rat hippocampus. J Neurosci 25:9162-9170.

Thorns V, Hansen L, Masliah E (1998) nNOS expressing neurons in the entorhinal cortex and hippocampus are affected in patients with Alzheimer's disease. Exp Neurol 150:14-20.

Wall MJ (2003) Endogenous nitric oxide modulates GABAergic transmission to granule cells in adult rat cerebellum. Eur J Neurosci 18:869-878,

Wang J, Irnaten M, Venkatesan P, Evans C, Baxi S, Mendelowitz D (2002) Synaptic activation of hypoglossal respiratory motoneurons during inspiration in rats. Neurosci Lett 332:195-199.

Wang S, Teschemacher AG, Paton JFR, Kasparov S (2006) The mechanism of nitric oxide action on inhibitory GABAergic signaling within the nucleus tractus solitarii. FASEB J 20:1537-1539.

Watanabe Y, Song T, Sugimoto K, Horii M, Araki N, Tokumitsu H, Tezuka T, Yamamoto T, Tozuda M (2003) Post-synaptic density-95 promotes calcium/calmodulin-dependent protein kinase II-mediated Ser847 phosphorylation of neuronal nitric oxide synthase. Biochem J 372:465-471.

West AR, Grace AA (2004) The nitric oxide-guanylyl cyclase signaling pathway modulates membrane activity states and electrophysiological properties of striatal medium spiny neurons recorded in vivo. J Neurosci 24:1924-1935.

Wua YJ, Dworetzky SI (2005) Recent developments on KCNQ potassium channel openers. Curr Med Chem 12:453-460.

Yang QZ, Hatton GI (1999) Nitric oxide via cGMP-dependent mechanisms increases dye coupling and excitability of rat supraoptic nucleus neurons. J Neurosci 19:4270-4279.

Yu WHA (1997) Regulation of nitric oxide synthase expression in motoneurons following nerve injury. Dev Neurosci 19:247-254.

Zhang L, Dawson VL, Dawson TM (2006) Role of nitric oxide in Parkinson's disease. Pharmacol Ther 109:33-41. 